\title{
Student Self Service System
}

\author{
T. Sheeba ${ }^{\mathrm{a}}$, S Hameetha Begum ${ }^{\mathrm{a}}$, Ibtisam saif Ali Al Harthy ${ }^{\mathrm{a}}$
}

\begin{abstract}
Nowadays we are living in the era of speed and technology. There are a lot of facilities to make the life easier. This project implements a student self-services system which allow student to be connected with World Wide Web. Student Self Service system provides all services needs to access to register for studying essential information that student will needs throughout their studies at College. The main goal of the project is to develop registration system for students at College. This project allows students in general to register for each semester by their own. The students need to access to the system through internet to register at College. This system is very suitable for student belonging in Muscat College as they can register every semester by their own. Also it saves time and effort for both student and staff. This system is a website application which is developed using ASP.NET framework and the result shows the successful completion of registration process and its related services.
\end{abstract}

Keywords: Registration, Electronic payment, Visual Studio, C\#, ASP.Net

\section{Introduction}

Students currently register in the Muscat College by signing the hard copy registration forms. All students have their responses manually entered into the academic registry. They are not currently able to directly access or update their own student record data such as programme, course and personal details. The purpose of this project is to produce an on-line process to allow both new and old students to register on line to the college. It provides all services needs to access to register for studying essential information that student will need throughout their studies at Muscat College. The mission and vision of the system is to make students wherever they live can register online on time effectively and efficiently. Also it provides simple way for students to register which save time and effort for both student and staff. The process will allow students to update and review all relevant information before finally accepting the college registration. It will provide realtime display to students for information held about them which will enable for students to maintain and update a selected set of data.

The students just need to register to system using computer connected with internet. It offers new students and old students to open an account on system and proceed in the registry.

The main objective of the proposed system is to create an efficient online student self-service system which will have the following service such as:

- Online registration process $\square$ Electronic payment process

- Directly access or update their own student record data such as programme, course, progress report, personal details etc.

- Directly access timetable after registration.
Some of the benefits that the proposed system offer is the registry will not need to undertake manual keying, the students will be able to view their own records, the paperbased process is removed and move to processing online, students will be informed promptly through e-mail, improved data quality as students will select options from drop down selection menus.

\section{Methodology}

The methodology adopted for the design and implementation of the project includes: Design the project requirements, Selection of appropriate technology and Implementation of modules (register student, payment, view student records, display time table, display and generate records etc.) and finally testing and evaluation.

a) Selection of appropriate technology a) ASP.NET [3] ASP.NET is a server-side framework of an open-source Web application designed for Web development to produce dynamic web pages. ASP.NET is a framework of free web sites to build a large web-sites and web applications using HTML, CSS, and JavaScript.

b) ASP.NET Web Pages

ASP.NET Web Pages offer a fast, approachable, and lightweight way to combine server code with HTML to generate dynamic web content, connect to databases, add video, link to social networking sites, and contain many more features which assistance user create attractive sites that conform to the latest web standards.

\section{c) Web Forms}

With ASP.NET Web Forms, user can build dynamic websites using a familiar drag-and-drop, event-driven model. A design surface and hundreds of controls as well 
as components let user rapidly build sophisticated, powerful UI-driven sites with data access [4].

d) SQL Server

The SQL Server is Microsoft's relational database management system (RDBMS). It's a full-featured database primarily designed to compete against competitors Oracle Database (DB) and MySQL.

\section{e) HTML, CSS and JavaScript}

The web page user realize in browser may be a combination of structure, style and interactivity. These jobs are undertaken by 3 different technologies, HTML, JavaScript, and CSS which browser knows how to interpret.

HTML: It marks the content-up into different structural types, like paragraphs, blocks, lists, images, tables, forms, comments etc.

CSS: tells the browser how each kind of element should be showed, that may vary for different media (such as screen, print or handheld device)

JavaScript: It tells the browser how to change the web page in response to events which happen (like clicking on something or changing the value in a form input) [7].

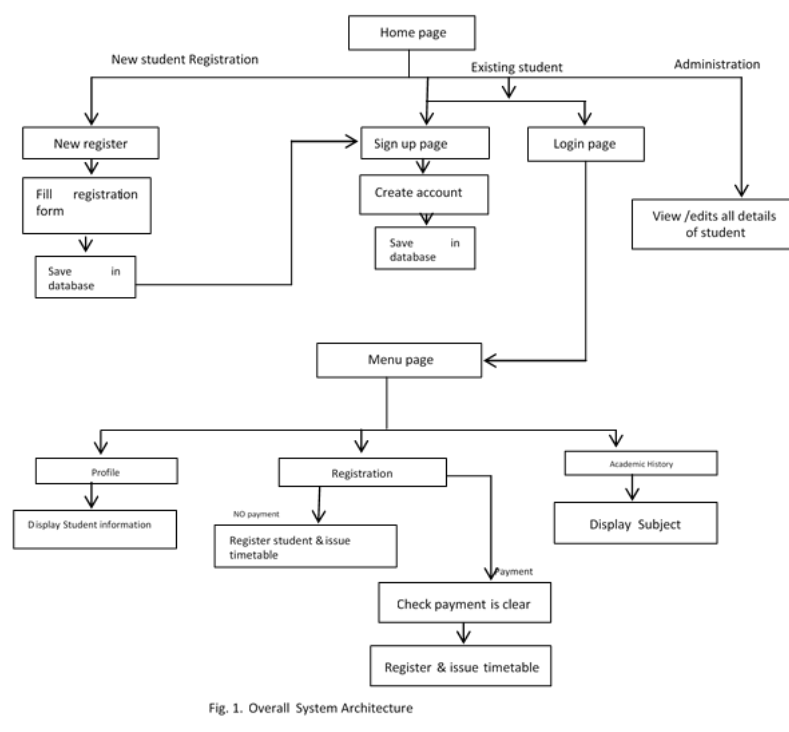

\section{Overall System Architecture}

Fig. 1 shows the overall structure of student self-service system. These are the operation that a student could reasonably expect to perform from the system. Fig. 1 shows the step and clear steps of what to be developed in the system. First, new students have to fill the registration form and the existing student has to enter into sign in page or login page. In menu page there are three options: profile to show student information, registration to register the student \& issue the timetable based on the payment and academic history to show subject completed.

\section{Implementation}

A. Student Self Service System a) Welcome Page

This is the first page of website design in student selfservices system. This page is the master page designed by CSS. In welcome page there are cards which describe the buttons and inside each button has a specific command. The main buttons in this page are register, signup and login. Register button will take to new student registration page. Also sign up will take to sign up page and login button will take to login page.

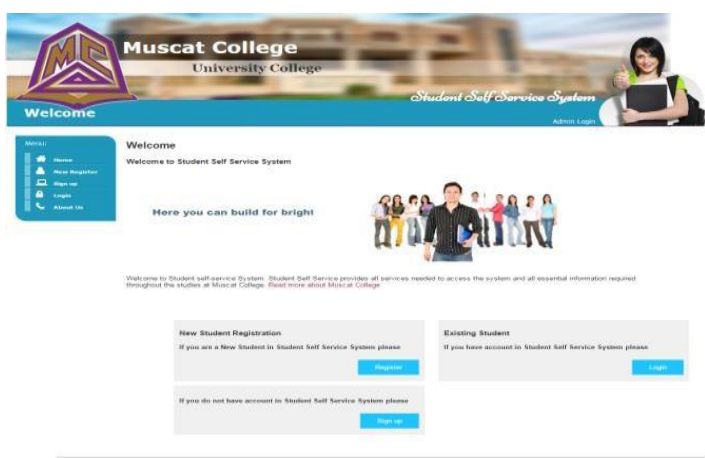

Fig. 2. Welcome Page

b) New Student Registration Page

This page is used by the new students who first register in the first year at Muscat College. In this page student must fill the necessary records which contains three buttons which are register, reset and back. Register button is linked with database. This button sends specific command to record all student information in the database. Reset button is used to clear every field in the new student registration page. Finally back buttons is used to close this page and return to welcome page.

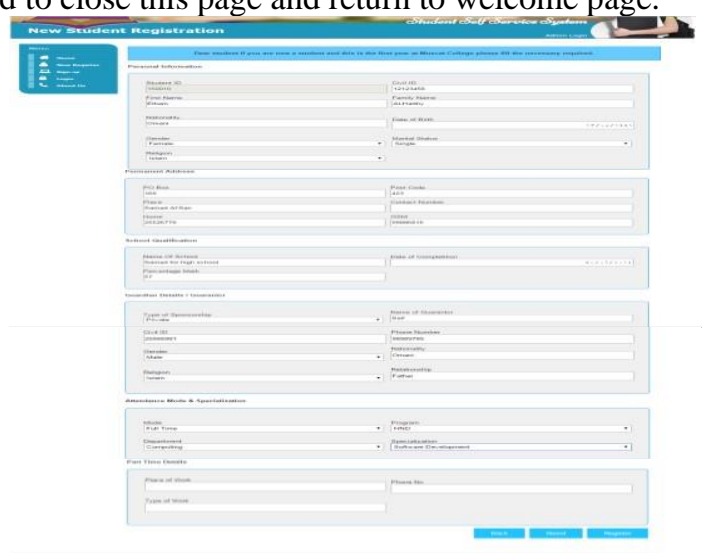


Fig. 3. New student registration page

\section{c) Sign up page}

This page appears after student finished the new student registration page. This page is necessary for student to open an account in student self-service system. The student must fill all the required fields. Sign up page contains three buttons which are sign up, reset and back. The sign up button has specific command which save all information of students in database. Reset button is used to clear all field in the sign up page and back button to return to welcome page.
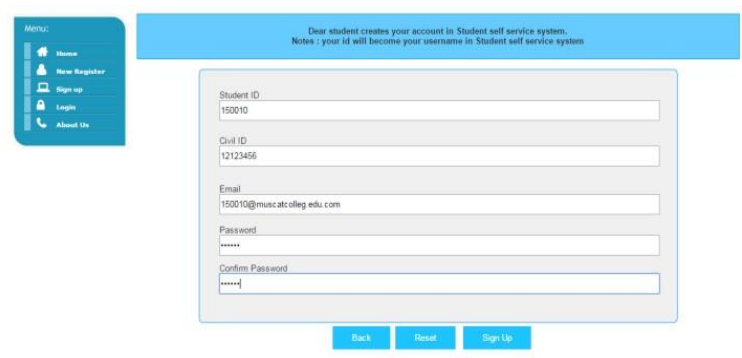

Fig. 4. Signup Page

\section{d) Student Menu Page}

This page appears for students after student login correctly. It contains menus in the left side of the navigation bar including home, module register, timetable, profile and academic history. In the top right corner of the page, appears the name of student and sign out button. Sign out button will exit from the system and return to welcome page. The middle of the page shows the year and semester.

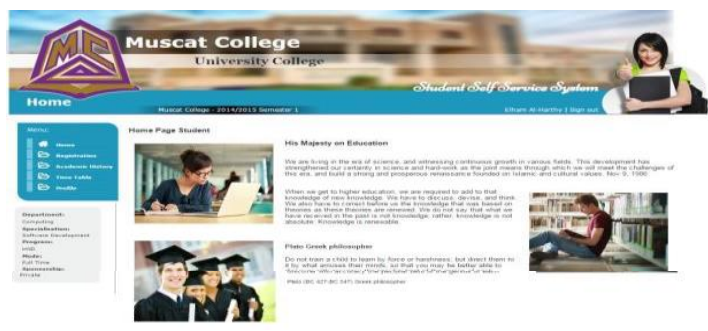

Fig. 5. Student Menu Page

e) Module registration page

This page is the registration page which shows three tables: module list, add modules and taken modules. Module list table shows the list of all modules offered in the programme. Student can select "select module" link to select the module and the link will add the module to the table "add modules" table. After student select all the preferred modules, the student have to press confirm selection button. This button has specific direction to take student to the e-payment page

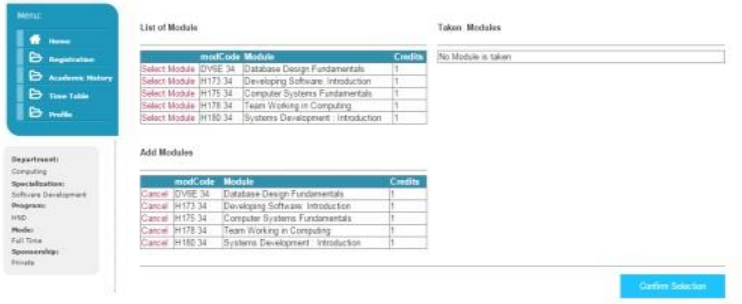

Fig. 6. Module Registration Page after Confirm Selection of Modules

f) E-payment page

This page appears after student confirm the selected module with the help of confirm selection button. This page shows the selected module with total price. The student has to press the Pay now button to open website of PayPal.
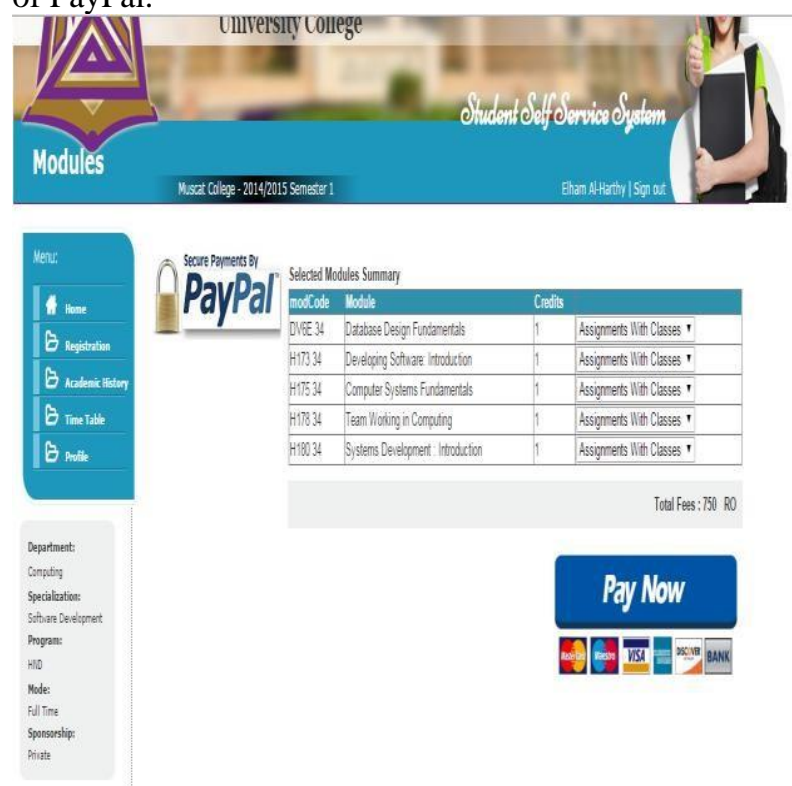

Fig. 7. E-Payment Page

g) PayPal

Student has to enter their own account in PayPal page. After login in, student will be shown the amount to transfer and the student has to press pay now button. 


\section{Muscat College Registration's Test Store}

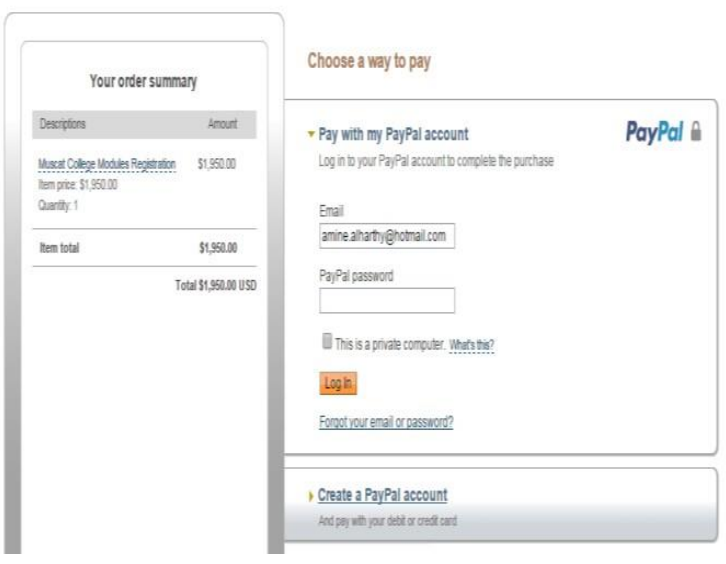

Fig. 8. PayPal Page

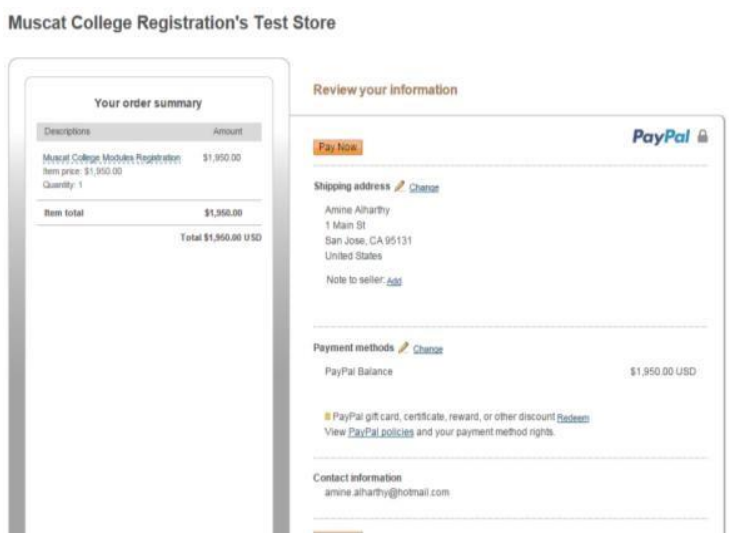

After student press the pay now button, a message will be shown declaring that the transfer is successful. In this page, button to go back to Muscat College will direct back to welcome page of student self-services system.

Muscat College Registration's Test Store

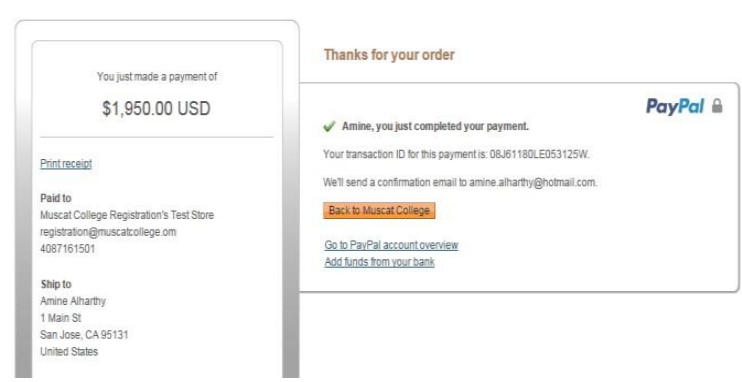

Fig. 9. Sucessful Completion of Payment
Below figure shows the page after paying the fees through PayPal with the message operation successfully completed with the amount paid on this semester.

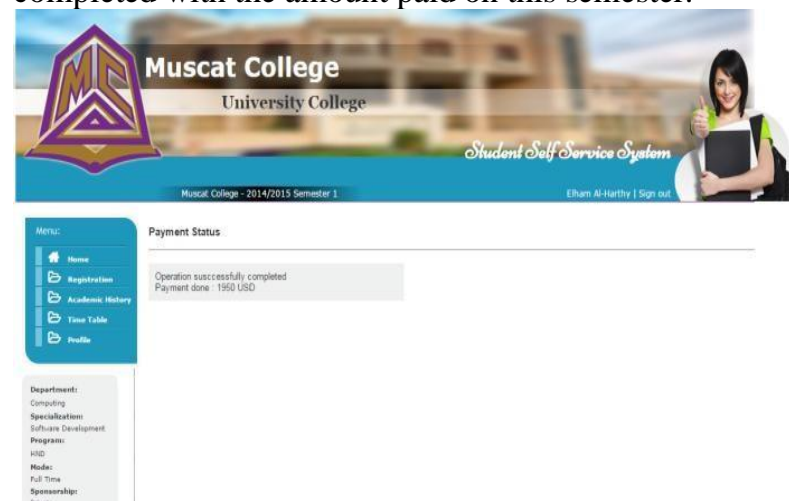

Fig. 10. Payment Status

h) Module Registration page After Payment

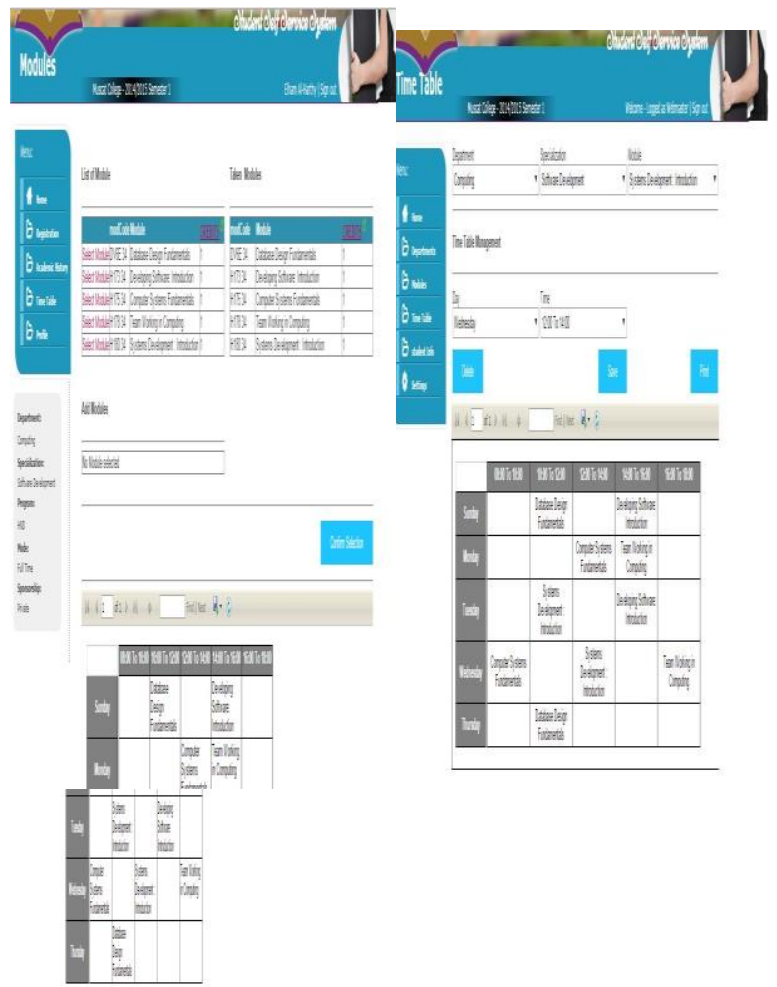

Fig. 11. Module Registration Page after Payment

After payment, the student will be returned to module registration page which shows the modules taken in current semester. 


\section{i) Home page of Administrator}

This page is used by the administrator. It appears after administrator login correctly into the system. It contains the menu in the left side of the navigation bar which includes home, department, module, timetable, student info and settings.

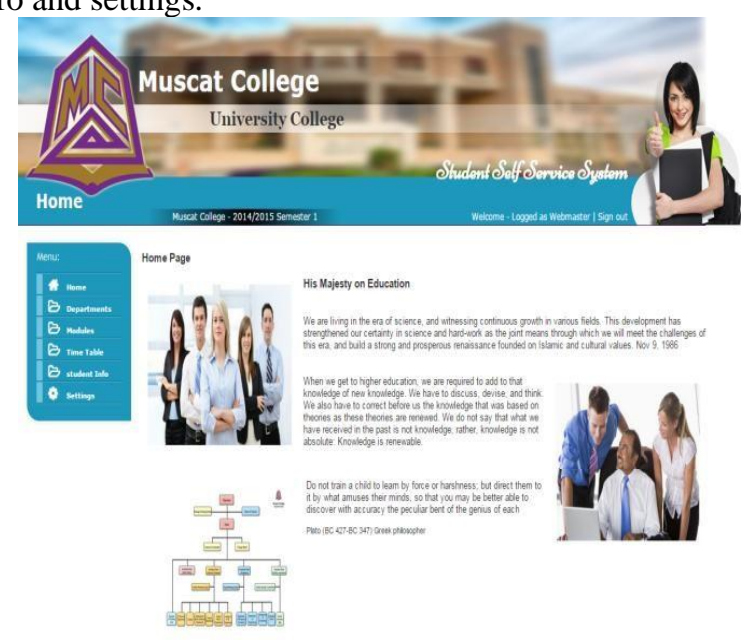

Fig. 12. Administrator Home Page

\section{j) Time table}

Administrator is responsible for organizing the time table for all departments. Administrator will choose the department, module for this specialization, day and time and click the save button.

College to register online. This system gives student an easy way to connect with college through the web. In this system, new students can fill the registration form and also can open an account in the system to login. When the student login to the real system they have some options such as viewing their personal information, registration for each semester and pay the fees through PayPal and viewing their academic history and the result. In this system, administrator can login to system. Administrator is the main controller of database and have all right to search, add, edit and delete the data. In other hand administrator is responsible to add modules and upload course to the registration page. Administrator is also responsible to record marks for all students and upload it into the student page.

\section{Future Scope}

In the future, an online testing exam for the new student can be conducted before filling the new student registration form. This exam is used to evaluate the level of student and determine if they have the skill to study foundation level or go to any specialization. Registration module can include "prerequisite" and "assessment only" options to check prerequisite modules and assessment only modules before registration. Also options can be included to see the percentages of attendance for each module. Also link with mobile phones can be included for the students to get message on exam dates, submission assessment and assignment.

\section{References}

[1] Ibra College of Technology. Available at http://www.ict.edu.om/. accessed on 30/4/2017.

[2] The University Of Jordon. available at http://www.ju.edu.jo/ar/arabic/home.aspx, accessed on 30/4/2017.

[3] What is ASP.Net?-Top12 Advantages of ASP.NET. Available at http://www.itegritygroup.com/asp-net-advantages/. Accessed on 30/4/2017.

[4] Building Web Sites in ASP.NET. Available at http://www.asp.net/getstarted/websites. Accessed 30/4/2017.

[5] ITegrity Areas of Coee Competence. Available at; http://www.itegritygroup.com/asp-net-advantages/. Accessed on 30/4/2017.

[6] Introduction to Microsoft SQL Server. Available at http://www.functionx.com/sqlserver/Lesson01.htm. Accessed on 30/4/2017.

[7] Web Design Form Scratch. Available at http://webdesignfromscratch.com/html-css/how-html-css-jsworktogether/. Accessed on 30/4/2017. 